\title{
Use of Quartz Sand to Produce Low Embodied Energy and Carbon Footprint Plaster
}

\section{Jiajian Chen*}

Department of Civil Engineering, Foshan University, 528000 Foshan, China

\section{Pui-Lam Ng}

Faculty of Civil Engineering, Vilnius Gediminas Technical University

Sauletekio ave. 11, LT-10223 Vilnius, Lithuania

\section{Roman Jaskulski, Wojciech Kubissa}

Faculty of Civil Engineering, Mechanics and Petrochemistry, Warsaw University of Technology 17 Łukasiewicza St., 09-400 Płock, Poland

${ }^{*}$ Corresponding author: chenjiajian@fosu.edu.cn

$\Gamma$ arossef http://dx.doi.org/10.5755/j01.sace.21.4.20005

Plaster is a widely adopted material in buildings. However, since the manufacturing of cement, a common component material in plaster, involves heating limestone and emits a lot of carbon dioxide, there is inherent problem pertaining to plaster that it is associated with a large amount of embodied energy and carbon footprint. One strategy to solve the problem is to employ quartz sand, an economic and abundant natural resource, to partially replace cement for plaster production to directly reduce the embodied energy and carbon footprint. To investigate the feasibility of practical use of quartz sand in plaster and quantify the effect on reducing the embodied energy and carbon footprint, a total of 30 plaster mixes with quartz sand content varying from $0 \%$ to $20 \%$ at various water/solid ratios were produced for laboratory testing, and the embodied energy and carbon footprint of each plaster mix were quantitatively estimated. Results demonstrated that the incorporation of suitable quartz sand in plaster could improve the workability for mixing and trowelling and reduce the embodied energy and carbon footprint as well as the cost at the same time.

Keywords: carbon footprint, embodied energy, plaster, quartz sand.

Cement plaster is a mixture of suitable plaster, sand, Portland cement and water. It is normally applied to masonry interiors and exteriors to achieve a smooth surface. As a widely used material, the cement plaster brings about major concern of sustainable development for the high embodied energy and carbon footprint derived mainly from cement manufacturing. Researchers have devoted enormous efforts to improve the environmental-friendliness and reduce the cost of cement plasters. The research findings in recent years are briefly introduced as follows.

Rodríguez et al. (2013) had tried adding ladle furnace slag into the plaster and experimentally showed that employing ladle furnace slag as a mineral aggregate would led to increase in density, vapour permeability, porosity, and decrease in adherence, durability and mechanical strength proportionately to the amount of plaster substituted by the ladle furnace slag. Their economic study also

\section{Introduction}

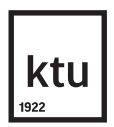

Journal of Sustainable Architecture and Civil Engineering Vol. 4 / No. 21 / 2017 pp. $75-81$

DOI 10.5755/j01.sace.21.4.20005 (c) Kaunas University of Technology 
suggested that the ladle furnace slag is viable in terms of cost-effectiveness and may be applied as plaster mortars for use in masonry. Aciu et al. (2014) illustrated that adding paper waste into plaster mortar could produce mortar with compressive strength falling in the respective range of category CS I or CS II in accordance with British Standard BS EN 998-1. Molnar et al. (2015) proved that using waste glass at $25 \%$ and $50 \%$ sand replacement levels yielded comparable physical and mechanical properties to the control sample and were the most suitable as plaster mortars, and they concluded that such mortars containing waste glass can be used as plaster mortars.

Andres et al. (2016) attempted to prepare plaster with clay and straw, which is waste from agriculture and most often is burnt in the fields with carbon dioxide emitted. They found that addition of straw would lower the mechanical strengths. Molnar and Manea (2016) demonstrated that the plaster mortar with $15 \%$ substitution of cement by marble powder has a 28 -day compressive strength of approximately $56 \%$ of the control plaster mortar mix without marble powder added. They concluded that replacing cement with marble powder can lower the cost of plaster mortar while all values of specific characteristics properties could meet the limits imposed by the standards. Torres and Matias (2016) reported that replacing sand with residuals from brick or roof tiles or pottery in plaster mortar could result in even higher compressive and flexural strengths. Bicer and Kar (2017) showed that employing waste expanded polystyrene foam as filling materials in the plaster with resin added to the gypsum could save the building heating and cooling energy at the cost of a lower compressive strength.

To lower the embodied energy and carbon footprint of plaster, the content of energy and carbon intensive ingredient, i.e. cement in the plaster shall be reduced with the workability and strength maintained to meet the practical requirements. Particularly, BS EN 998-1 sets minimum compressive strength value to be $0.4,1.5,3.5$ and $6 \mathrm{MPa}$ for categories CS I, CS II, CS III and CS IV mortar, respectively. As quartz is the second most abundant mineral only behind feldspar in Earth's continental crust (Anderson and Anderson 2010), the use of quartz sand as cement replacement could be a wise strategy for production of environmental-friendly and economical plaster. However, literature review showed that so far there has been very little study on the possibility of using quartz sand as cement replacement for plaster production.

In the present study, the quartz sand was added as partial cement replacement and its effects on the workability and strength were evaluated by trial mixing at different water/solid (W/S) ratios, and the embodied energy and carbon footprint of each sample mix were calculated. Finally, the viability of such strategy of using quartz sand as partial cement replacement for plaster production is discussed and appraised.

Materials

Both the ordinary Portland cement (OPC) and quartz sand were obtained in Guangdong Province of China. The OPC was of strength class $32.5 \mathrm{~N}$. The quartz sand used in this study is normal quartz sand ground from natural quartz stone in China. Its chemical composition is mainly $\mathrm{SiO}_{2}$. The solid densities of the OPC and quartz sand had been measured in accordance with British Standard BS EN 1097-3: 1998 as $3100 \mathrm{~kg} / \mathrm{m}^{3}$ and $2600 \mathrm{~kg} / \mathrm{m}^{3}$, respectively. The specific surface area of the OPC was calculated as $1.14 \times 10^{6} \mathrm{~m}^{2} / \mathrm{m}^{3}$ (equivalent to $368 \mathrm{~m}^{2} / \mathrm{kg}$ ) based on the particle size distributions measured by a laser diffraction particle size analyzer. The median particle size value of the OPC was measured to be $9.34 \mu \mathrm{m}$, while the quartz sand was finer than $180 \mu \mathrm{m}$ according to the supplier. The embodied energy and carbon footprint of all the materials used are tabulated in Table 1.

In this study, a total of 30 plaster mixes with and without quartz sand were produced for workability and strength measurement. The quartz sand content, expressed as a percentage by mass of solid in plaster, was varied from 0 to $20 \%$ in increments of $5 \%$; whereas the W/S ratio, expressed as a ratio by mass, was varied from 0.35 to 0.60 in increments of 0.05 . Hence, there were 5 different quartz sand contents and 6 different W/S ratios. Altogether $5 \times 6=30$ mixes were produced for 
testing. All sample preparation and testing procedures were carried out in a laboratory maintained at a temperature of $24 \pm 2^{\circ} \mathrm{C}$.

The workability of the plaster mixes is represented by the semi-dynamic and dynamic flowability, which could reflect the ease of trowelling. The semi-dynamic flowability was measured in terms of the flow spread using the mini slump cone test (Okamura et al. 2000). The dynamic flowability was measured in terms of the flow rate using the Marsh cone test (Aïtcin 1998). The mini slump cone adopted was the same as that used by Okamura and Ouchi (2003), whereas the Marsh cone adopted was the same as that specified in British Standard BS EN 445: 1997. To measure the strength, three $70.7 \mathrm{~mm}$ cubes were made from each plaster sample. The cubes were made by placing the fresh mix into a cube mould. At one day after casting, the moulds were removed. The strength result of each plaster mix was taken as the average strength of three cubes tested at the same time.

\section{Workability}

The flow spread results are plotted against the W/S ratio for various quartz sand contents in Fig. 1. From the flow spread curves, it is evident that the addition of quartz sand as cement replacement gradually increased the flow spread of the plaster mix. For instance, the addition of $20 \%$ quartz sand increased the flow spread from 23.0 to $77.5 \mathrm{~mm}$ at a W/S ratio of 0.40 and increased the flow spread from 147.5 to $171.0 \mathrm{~mm}$ at a W/S ratio of 0.50 . During the flow spread measurement, no bleeding occurred for all the plaster mixes in this study. This observation indicated that at a W/S ratio not higher than 0.60 , the addition of up to $20 \%$ quartz sand as cement replacement could improve the workability and would not lead to bleeding.

Likewise, the flow rate results are plotted against the W/S ratio for various quartz sand contents in Fig. 2. From the flow rate curves, it is obvious that the addition of quartz sand as cement replacement gradually increased the flow rate of the plaster mix. For instance, the addition of $20 \%$ quartz sand increased the flow rate from 36.3 to $72.8 \mathrm{ml} / \mathrm{s}$ at a W/S ratio of 0.50 and increased the flow rate from 65.3 to $94.7 \mathrm{ml} / \mathrm{s}$ at a W/S ratio of 0.60 . The increase in flowability due to the addition of quartz sand may be attributed to the significant decrease in specific surface area of the solid when cement was partially replaced by quartz sand, which at the
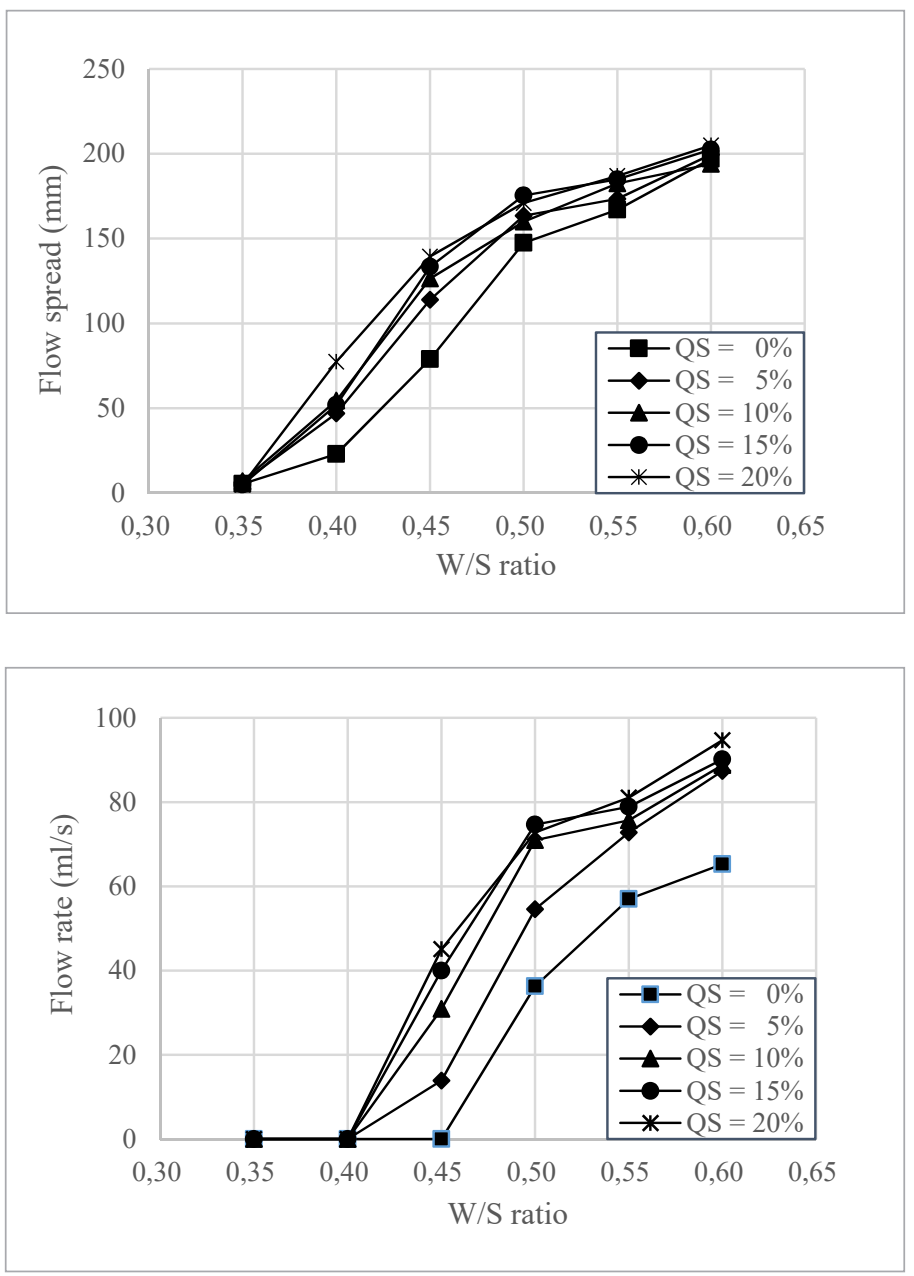

\section{Test methods}

\section{Test results}

Fig. 1

Variation of flow spread with $\mathrm{W} / \mathrm{S}$ ratio at various quartz sand contents

Fig. 2

Variation of flow rate with W/S ratio at various quartz sand contents 
same water content tends to increase the water film coating the solid particles in the plaster mix. Generally, the increase in both flow spread and flow rate were proportionally larger at low W/S ratio. This is because addition of quartz sand would increase the packing density of the solid mix by widening the particle size distribution range, and would at the same water content provide proportionally more excess water (the water in excess of that required to fill voids between solid particles) at low W/S ratio (Kwan and Chen 2013).

\section{Strength}

The 28-day compressive strength results are plotted against the W/S ratio for various quartz sand contents in Fig. 3. Results showed that the strength decreased as the W/S ratio increased, and that the addition of quartz sand as cement replacement decreased the strength. These observations are in accordance with the expectations. It is noted that the decrease in strength due to addition of quartz sand was proportionally larger at higher W/S ratio. This is because at low W/S ratio, water would be the limiting reactant of hydration reaction and there would be relatively large amount of unhydrated
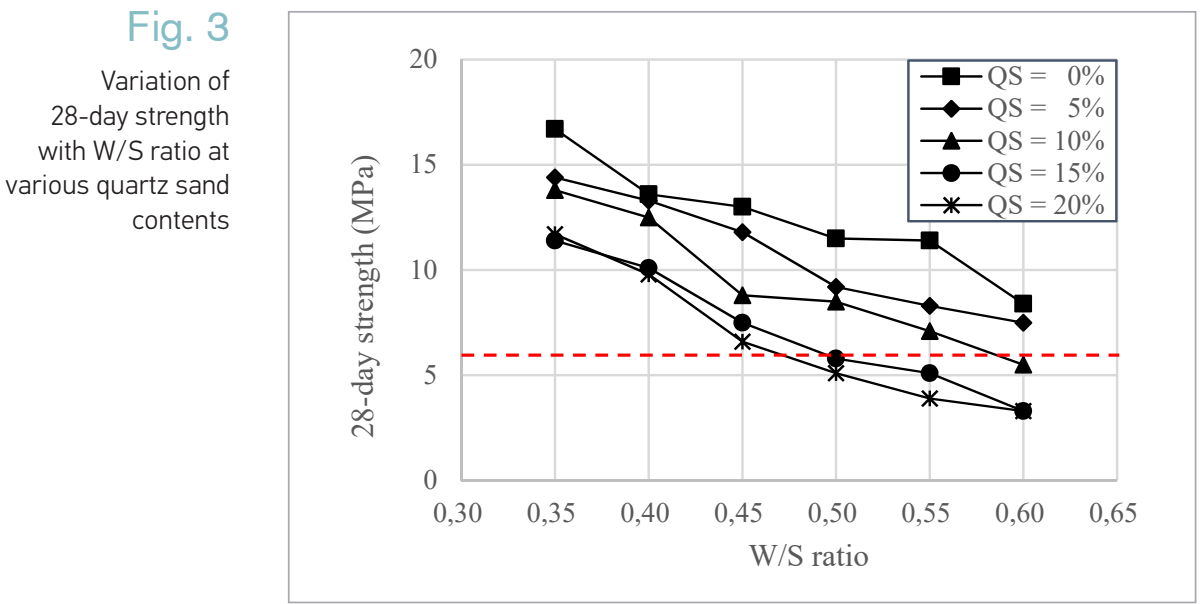

cement, replacing cement by quartz sand would decrease proportionally less amount of hydrated cement.

In Fig. 3, a dotted line is drawn at the strength level of $6 \mathrm{MPa}$, which is the required strength of mortar to be classified as the highest category CS IV according to BS EN 998-1. It should be noted that a compressive strength below $6 \mathrm{MPa}$ may still satisfy the requirements of other categories,

for example, category CS I requires a strength of 0.4 to $2.5 \mathrm{MPa}$ and category CS II requires a strength of 1.5 to $5.0 \mathrm{MPa}$. It can be seen from the results that addition of quartz sand up to $20 \%$ at $\mathrm{W} / \mathrm{S}<0.50$ or up to $10 \%$ at W/S $<0.60$ could produce plaster mixes meeting the strength requirement of category CS IV. All the plaster mixes produced in this study meet the strength requirement of at least category CS II.

\section{Embodied energy and carbon footprint}

The manufacturing of cement involves heating of limestone to incept fusion of clinker. This process emits a lot of carbon dioxide and aggravates global warming. According to Mehta and Walters (2008), the production of one ton of cement releases approximately 0.75 ton of carbon dioxide gas. On this basis, Mehta and Meryman (2009) estimated that cement production accounts for $6-7 \%$ of the total global greenhouse gas emission from all anthropogenic sources. This situation may become even worse because the economic growth of developing countries is likely to boost the demand of cement. Compared to cement, quartz sand is more energy efficient and environmen-

\begin{tabular}{rl|c|c} 
Table 1 & \multicolumn{1}{c|}{ Item } & Embodied energy $(\mathrm{kJ} / \mathrm{kg})$ & Carbon footprint $\left(\mathrm{kg} \mathrm{CO}_{2} / \mathrm{kg}\right)$ \\
\cline { 2 - 4 } $\begin{array}{r}\text { Embodied energy } \\
\text { and carbon } \\
\text { footprint per unit } \\
\text { weight of materials }\end{array}$ & OPC & 4.500 & 0.730 \\
\cline { 2 - 4 } & Quartz sand & 0.850 & 0.020 \\
\cline { 2 - 4 } & Water & 0.010 & 0.001 \\
\cline { 2 - 4 }
\end{tabular}
tal-friendly. Typical values of embodied energy and carbon footprint per unit weight of $\mathrm{OPC}$, quartz sand and water are listed in Table 1 (Hammond and Jones 2008). Clearly, by replacing part of 
the cement with quartz sand, the embodied energy and carbon footprint of plaster can be substantially reduced. Such beneficial effects are quantitatively evaluated in the following.

The embodied energy of the plaster mixes is evaluated and plotted against the W/S ratio for various quartz sand contents in Fig. 4. Results showed that addition of $20 \%$ quartz sand could reduce the embodied energy by $17.3 \%$ to $17.7 \%$ for the range of W/S ratios adopted in this study.

Likewise, the carbon footprint of the plaster mixes is evaluated and plotted against the W/S ratio for various quartz sand contents in Fig. 5 . Results showed that addition of $20 \%$ quartz sand could reduce the carbon footprint by $20.5 \%$ to $20.9 \%$ for the range of $\mathrm{W} / \mathrm{S}$ ratios adopted in this study.
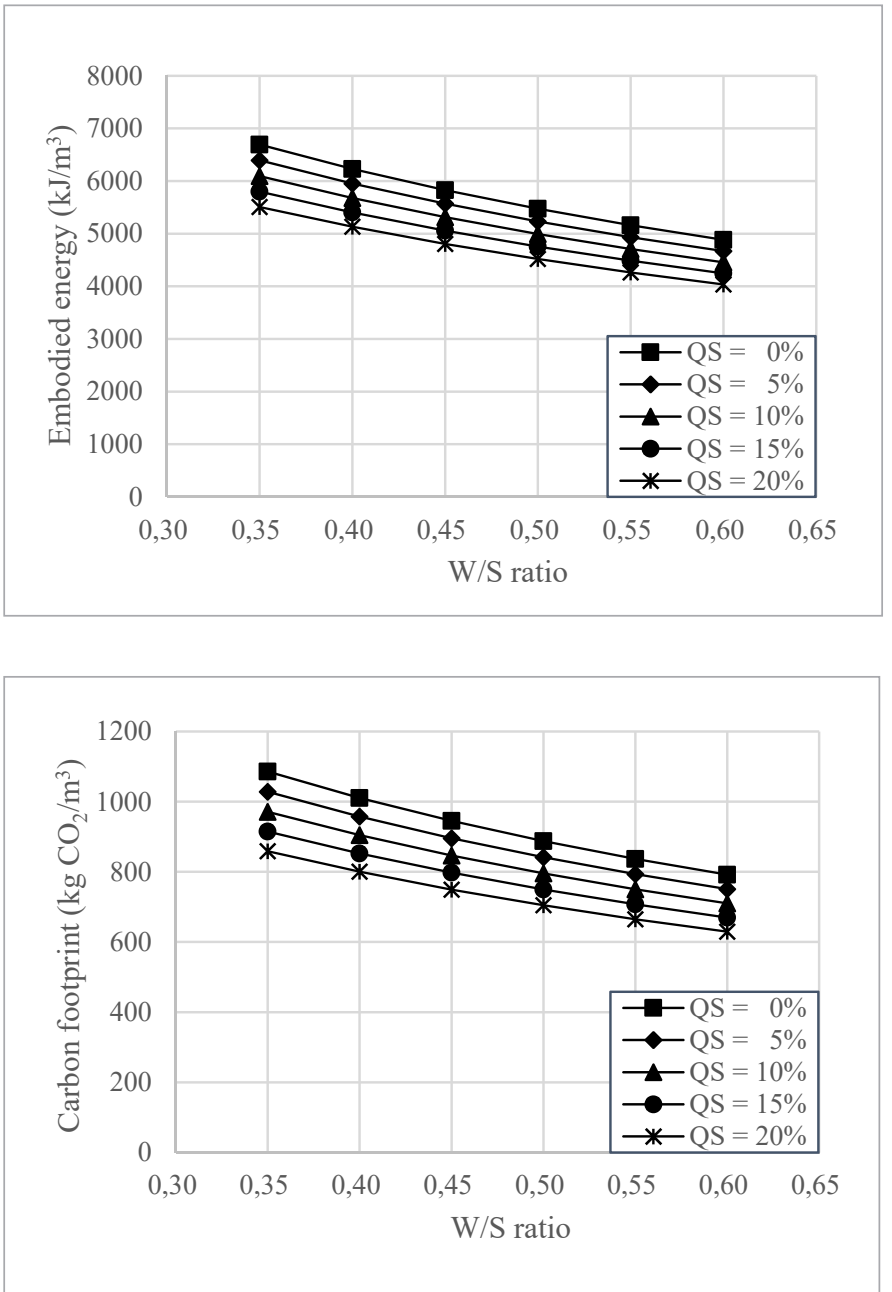

Fig. 4

Variation of embodied energy with $\mathrm{W} / \mathrm{S}$ ratio at various quartz sand contents
Fig. 5

Variation of carbon footprint with W/S ratio at various quartz sand contents
It is apparent from the above results that the use of quartz sand as cement replacement in plaster production would improve the workability, lower the strength, reduce the embodied energy and carbon footprint. From the practical perspective, a relatively high workability is beneficial for the mixing and trowelling processes, while the strength is less important given that the required minimum strength is achieved.

To gain insight into the relationship between workability and other properties of plaster, the variation of 28-day strength with flow rate performance at various quartz sand contents is plotted in Fig. 6 , in which the dotted line indicates the minimum strength requirement of category CS IV mortar, i.e. $6 \mathrm{MPa}$. The concurrent strength and flow rate performance curves show that rational addition of quartz

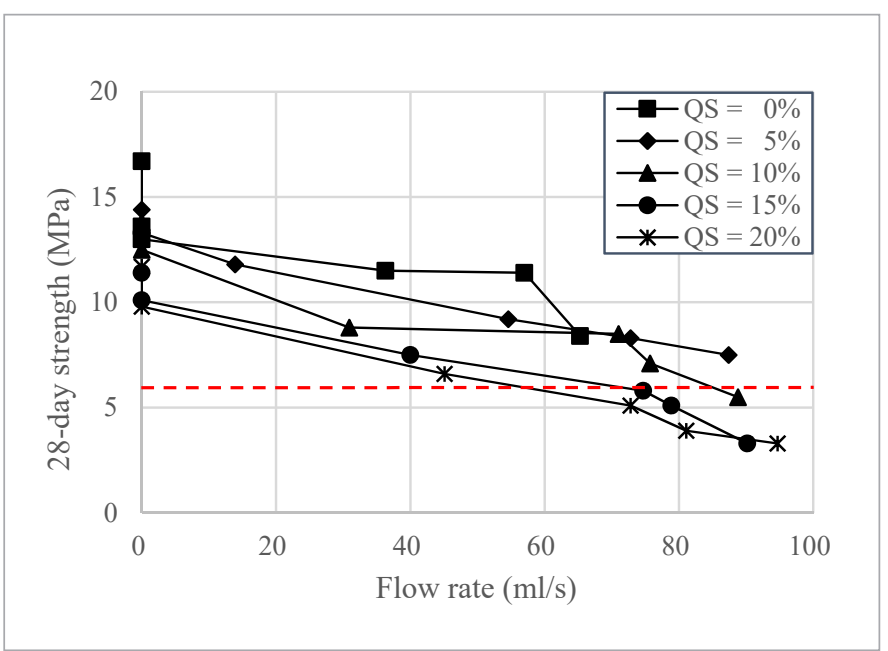

\section{Discussion}

Fig. 6

Concurrent strength and flow rate performance 
Fig. 7

Concurrent embodied energy and flow rate performance

Fig. 8

Concurrent carbon footprint and flow rate performance
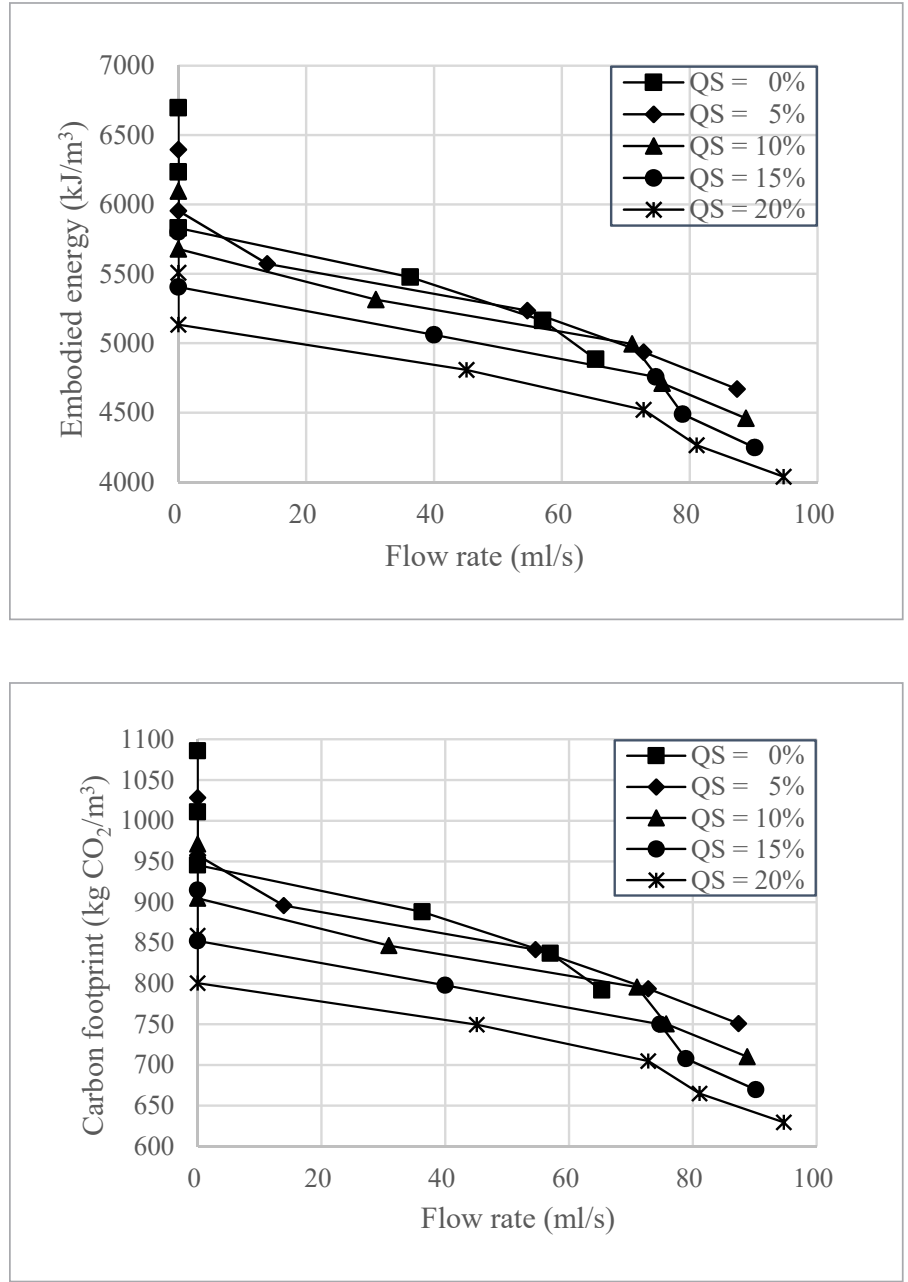

bodied energy and carbon footprint, and reduce the cost at the same time.

Finally, it is the authors' view that the use of quartz sand for performance improvement and sustainable development should not be limited to plaster. In fact, since the quartz sand has a particle size larger than the OPC and smaller than fine aggregate, it should be able to increase the packing density of solid skeleton in the mortar and mortar phase in concrete, and thus improve the performance (Aïtcin et al. 2016). Future research along this line is highly recommended.

Experimental investigation on using quartz sand to produce low embodied energy and carbon footprint plaster has been performed. On the basis of the experimental results, it is concluded that the rational use of quartz sand as cement replacement can, under a necessary strength requirement of given mortar category, improve the workability to ease the mixing and trowelling, reduce the embodied energy and carbon footprint for better sustainability, and at the same time reduce the cost for more affordable construction. Further research to capitalise the beneficial effects of utilising quartz sand is recommended.

The work presented in this paper was supported by funding from Guangzhou Science Research Project (Project No. 201607010329), College and Hospital Research Platform of Foshan City (Project No. 2016AG100341), and Marie Skłodowska-Curie Actions of the European Commission (Project No. 751461). 
Aciu C., Varvara D.A.I., Cobirzan N., Balog A. Recycling of paper waste in the composition of plastering mortars. Procedia Technology, 2014; 12: 295300. https://doi.org/10.1016/j.protcy.2013.12.489

Aïtcin P.-C. High-Performance Concrete. London and New York: E\&FN Spon; 1998. https://doi. org/10.4324/9780203475034

Aïtcin P.-C., Wilson W., Mindess S. Increasing the strength of concrete made with blended cements. Concrete International, 2016; 38(8): 49-52.

Anderson R.S., Anderson S.P. Geomorphology: The Mechanics and Chemistry of Landscapes. Cambridge: Cambridge University Press; 2010. https:// doi.org/10.1017/CB09780511794827

Andres D.M., Manea D.L., Fechete R., Jumate E. Green plastering mortars based on clay and wheat straw. Procedia Technology, 2016; 22: 327-334. https://doi.org/10.1016/j.protcy.2016.01.105

Bicer A., Kar F. Thermal and mechanical properties of gypsum plaster mixed with expanded polystyrene and tragacanth. Thermal Science and Engineering Progress, 2017; 1: 59-65. https://doi.org/10.1016/j. tsep.2017.02.008

Hammond G.P., Jones C. Inventory of Carbon \& Energy (ICE). Bath: University of Bath; 2008.

Kwan A.K.H., Chen J.J. Adding fly ash microsphere to improve packing density, flowability and strength of cement paste. Powder Technology, 2013; 234: 1925. https://doi.org/10.1016/j.powtec.2012.09.016
Mehta P.K., Meryman H. Tools for reducing carbon emissions due to cement consumption. Structures, 2009; 1: 11-15.

Mehta P.K., Walters M. Roadmap to a sustainable concrete construction industry. The Construction Specifier, 2008; 61(1): 48-57.

Molnar L.M., Manea D.L. New types of plastering mortars based on marble powder slime. Procedia Technology, 2016; 22: 251-258. https://doi. org/10.1016/j.protcy.2016.01.076

Molnar L.M., Manea D.L., Aciu C., Jumate E. Innovative plastering mortars based on recycled waste glass. Procedia Technology, 2015; 19: 299-306. https://doi.org/10.1016/j.protcy.2015.02.043

Okamura H., Ouchi M. Self-compacting concrete. Journal of Advanced Concrete Technology, 2003; 1(1): 5-15. https://doi.org/10.3151/jact.1.5

Okamura H., Ozawa K., Ouchi M. Self-compacting concrete. Structural Concrete, 2000; 1(1): 3-17. https://doi.org/10.1680/stco.2000.1.1.3

Rodríguez A., Gutiérrez-González S., Horgnies M., Calderón V. Design and properties of plaster mortars manufactured with ladle furnace slag. Materials and Design, 2013; 52: 987-994. https://doi. org/10.1016/j.matdes.2013.06.041

Torres I., Matias G. Sustainable mortars for rehabilitation of old plasters. Engineering Structures, 2016; 129: 11-17. https://doi.org/10.1016/j.engstruct.2016.07.009

\section{JIAJIAN CHEN}

Assoc. Professor

Foshan University, Department of Civil Engineering

\section{Main research area}

High-performance concrete,

Environmentallyfriendly concrete

\section{Address}

18 Jiangwan

Rd, Foshan City, Guangdong Province, China

Tel. +86-13450891042

E-mail: chenjiajian@ fosu.edu.cn

\section{PUI-LAM NG \\ Adjunct Professor \\ Vilnius Gediminas \\ Technical University, \\ Faculty of Civil \\ Engineering}

Main research area

Sustainable concrete materials and structures, Concrete science and nanotechnology, High-performance cementitious materials

\section{Address}

Sauletekio Al. 11, Vilnius LT-10223, Lithuania Tel. +370-62423921/ +852-95875310 E-mail: irdngpl@gmail. com
ROMAN JASKULSKI

Assist. Professor

Warsaw University of

Technology, Faculty of Civil Engineering,

Mechanics and

Petrochemistry

Main research area

Thermal properties of concrete, Sustainable concrete materials, Recycling and re-use of industrial waste in cement composites

\section{Address}

17 Łukasiewicza St., 09-400 Płock, Poland Tel. +48-243672182

E-mail: roman. jaskulski@pw.edu.pl
WOJCIECH KUBISSA

Assist. Professor

Warsaw University of

Technology, Faculty

of Civil Engineering,

Mechanics and

Petrochemistry

\section{Main research area}

Sustainable development in concrete technology,

Materials engineering,

Civil engineering

\section{Address}

17 Łukasiewicza St., 09-

400 Płock, Poland

Tel. +48-242626254

E-mail: wojciech.

kubissa@pw.edu.pl

\section{About the authors}

